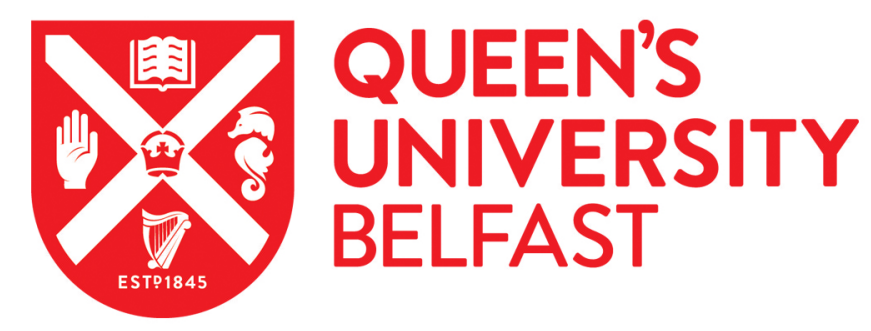

\title{
Measurement of the compressive crack resistance curve of composites using the size effect law
}

Catalanotti, G., Xavier, J., \& Camanho, P. P. (2014). Measurement of the compressive crack resistance curve of composites using the size effect law. Composites Part A: Applied Science and Manufacturing, 56, 300-307. https://doi.org/10.1016/j.compositesa.2013.10.017

Published in:

Composites Part A: Applied Science and Manufacturing

Document Version:

Peer reviewed version

Queen's University Belfast - Research Portal:

Link to publication record in Queen's University Belfast Research Portal

Publisher rights

Copyright 2014 Elsevier.

This manuscript is distributed under a Creative Commons Attribution-NonCommercial-NoDerivs License

(https://creativecommons.org/licenses/by-nc-nd/4.0/), which permits distribution and reproduction for non-commercial purposes, provided the author and source are cited.

\section{General rights}

Copyright for the publications made accessible via the Queen's University Belfast Research Portal is retained by the author(s) and / or other copyright owners and it is a condition of accessing these publications that users recognise and abide by the legal requirements associated with these rights.

Take down policy

The Research Portal is Queen's institutional repository that provides access to Queen's research output. Every effort has been made to ensure that content in the Research Portal does not infringe any person's rights, or applicable UK laws. If you discover content in the Research Portal that you believe breaches copyright or violates any law, please contact openaccess@qub.ac.uk. 


\title{
Measurement of the compressive crack resistance curve of composites using the size effect law
}

\author{
G. Catalanotti ${ }^{\mathrm{a}, *}$, J. Xavier $^{\mathrm{b}}$, P.P. Camanho ${ }^{\mathrm{a}}$ \\ ${ }^{a}$ DEMec, Faculdade de Engenharia, Universidade do Porto, Rua Dr. Roberto \\ Frias, 4200-465, Porto, Portugal \\ ${ }^{\mathrm{b}}$ CITAB, University of Trás-os-Montes e Alto Douro, Apartado 1013, 5001-801 \\ Vila Real, Portugal.
}

\begin{abstract}
This paper presents a new methodology to measure the compressive crack resistance curve of the longitudinal plies of carbon-epoxy laminates. The methodology is based on three main steps: the first one corresponds to the determination of the energy release rate of cross-ply laminates with two edge cracks using a parametric finite element model. The energy release rate is used in the definition of a relation between the crack resistance curve and the size effect. Finally, experimental tests are performed in scaled double-edge notched specimens to quantify the size effect law, thus proving the last piece of information required to define the crack resistance curve. The full crack resistance curve is obtained for the IM7-8552 carbon epoxy composite material. The methodology proposed in this paper overcomes the inherent limitations of the existing test methods, and it serves as the basis for the identification of cohesive laws used in some analysis models.
\end{abstract}

Key words:

A. Polymer-matrix composites (PMCs), B. Fracture toughness, C. Analytical modelling, D. Mechanical testing 


\section{$1 \quad 1$ Introduction}

2 The development of a new generation of tougher composite materials presents

3 several challenges to the existing methods for the measurement of the fracture

4 toughness associated with cracks that propagate perpendicularly to the fiber

5 direction. The intra-laminar fracture toughness is relevant not only for mate-

6 rial screening and qualification, but also to define the softening laws used in

7 recent analysis models that predict the ultimate strength of composite struc-

8 tures $[1-5]$.

9 The Compact Tension (CT) test specimen $[6,7]$ is normally used to measure

10 the fracture toughness and the crack resistance curve (R-curve) of compos-

11 ite materials reinforced by unidirectional fibres. While reliable results can be

12 obtained for brittle material systems using appropriate data reduction meth-

13 ods $[8,7]$, the introduction of tougher resins leads to higher loads for crack

14 propagation, which may cause buckling of the unnotched end of the CT test

15 specimen [9].

${ }_{16}$ There is also the need to measure the fracture toughness and the correspond-

17 ing R-curve associated to the propagation of a kink-band, which shows a

18 crack-like behaviour [10-12] with an R-curve that results from the broadening

19 of the damage height [11]. It is considered here that the compact compres-

20 sion test specimen is inadequate to measure the compressive crack resistance

${ }_{21}$ curves of polymer composite materials. In fact, the correction factor used in

22 the data reduction method of the compact compression test method to calcu-

23 late the energy release rate is the same as that used in the compact tension

\footnotetext{
* Corresponding author

Email address: giuseppe.catalanotti@fe.up.pt (G. Catalanotti).
} 
method. However, the contact tractions that occur on the crack faces during a compact compression test render the data reduction method inaccurate. This was demonstrated in a previous investigation [7] where the $\mathcal{J}$-integral around the crack tip was computed using digital image correlation. It was shown [7] that the R-curve of the compact test specimens using the $\mathcal{J}$-Integral and the data reduction method proposed by Pinho et al. [6] are virtually the same for tension but not for compression.

It should also be noted that the compact compression specimen triggers diffused damage during the propagation of the kink-band, artificially increasing the value of the measured fracture toughness, and that it is not possible to identify the location of the tip of the kink band [7]. Therefore, it is considered that while the compact compression test method may be used to measure the initial value of the fracture toughness it does not provide reliable information for the generation of the R-curve.

This means that the analysts have no reliable test methods to measure some of the required material properties, namely the fracture toughness related with the propagation of a kink-band and the corresponding R-curve.

1 This fact provides the motivation for this paper, whose objective is to propose a new methodology to obtain the R-curve of composite materials that fail by the propagation of a kink-band. The approach proposed is based on the relation between the size effect law and the R-curve, and it will be presented in the following order: section 2 describes the analytical model that relates the size effect law obtained in cross-ply laminates with two edge notched to the R-curve. Section 3 presents the details of the compression tests performed in the double-edge notched specimens manufactured using IM7-8552 carbonepoxy. Section 4 combines the analytical model and the test results to fully 
50

51

52

53

54 is $3 w$, and $a_{0}$ is the initial crack length.

55

56

57 axes of the material, the energy release rate $(\mathrm{ERR})$ in mode $\mathrm{I}$ for a crack

58 propagating in the $x$-direction reads [13]:

$$
\mathcal{G}_{I}=\left(s_{11} s_{22} \frac{1+\rho}{2}\right)^{1 / 2} \lambda^{-1 / 4} \mathcal{K}_{I}^{2}
$$

59 where $s_{l m}$ are the components of the compliance matrix computed in the $x$ -

${ }_{60} y$ coordinate system, $\mathcal{K}_{I}$ is the stress intensity factor, and $\lambda, \rho$ are the two

61 dimensionless elastic parameters defined as:

$$
\lambda=\frac{s_{11}}{s_{22}}, \quad \rho=\frac{2 s_{12}+s_{66}}{2 \sqrt{s_{11} s_{22}}}
$$

${ }_{62}$ Suppose that the crack is propagating in a $[0 / 90]_{n s}$ cross-ply laminate. In this

63 case, $s_{11}=s_{22}, \lambda=1$ and equation (1) reads:

$$
\mathcal{G}_{I}=\frac{1}{E} \sqrt{\frac{1+\rho}{2}} \mathcal{K}_{I}^{2}
$$


where $E$ is the laminate Young's modulus along the $x$ (or $y$ ) direction.

The stress intensity factor of the double edge notched specimen shown in Figure 1 is a function of $\rho$, of the remote stress $\sigma$, and of the shape and the size of the specimen:

$$
\mathcal{K}_{I}=\sigma \sqrt{w} \sqrt{\phi(\alpha, \rho)}
$$

where $\alpha=a / w$ is the shape-parameter and $\phi(\alpha, \rho)$ is the correction factor for the geometry and orthotropy of the material. Substituting (4) in (3) the energy release rate reads:

$$
\mathcal{G}_{I}=\frac{1}{E} \sqrt{\frac{1+\rho}{2}} \sigma^{2} w \phi(\alpha, \rho)=\frac{1}{4 w E} \sqrt{\frac{1+\rho}{2}}\left(\frac{P}{t}\right)^{2} \phi(\alpha, \rho)
$$

where $t$ is the thickness of the specimen.

Following the approach proposed in [7] the dimensionless function $\phi(\alpha, \rho)$ can be defined for the problem under consideration using the Finite Element Method (FEM). For this purpose a parametric Finite Element model was created using Python [14] together with Abaqus 6.8-3 Finite Element code [15].

In this model the characteristic distance $w$ is taken constant and equal to the unity, while the variables are: i) the shape parameter or, in other words, the crack length $0<\alpha<1$; ii) the dimensionless parameter $\rho$ that takes into account the effect of the orthotropy of the material $(0 \leq \rho \leq 20)$. There is no need to take into account $\lambda$ because for the layup that was chosen (balanced cross ply) its value is constant and equal to one; therefore $\lambda$ is not accounted for in the calibration of the model. Figure 2 shows the mesh of the finite 
83

element model used to define the function $\phi$.

84

[Fig. 2 about here.]
85

86

87

88

Taking advantage of the symmetry of the problem, only one quarter of the specimen was modeled. The 4-node quadratic, reduced integration element, CPS4R, is used.

The displacement $u_{y}$ is applied on the top face of the model and represents the loading condition that will be used in the experiments. The nodes on the top faces are free to move in $x$ direction; this means that a frictionless contact occurs between the specimen and the loading system. The Virtual Crack Closure Technique (VCCT) [16] is used to compute the energy release rate at the crack tip, $\mathcal{G}_{I}$. The applied load $P$ is calculated summing the reactions at the nodes.

Using the results obtained in the FE analysis the correction factor $\phi$ is approximated by the following polynomial:

$$
\phi(\alpha, \rho)=\frac{\alpha}{1-\alpha} \sum_{i=1}^{M} \sum_{j=1}^{N} \Phi_{i j} \rho^{j-1} \alpha^{i-1}
$$

95 where $\Phi_{i j}$ is the element of the matrix $\boldsymbol{\Phi}$ at the row $i$ and at the column $j$, 96 and $M$ and $N$ are the number of rows and columns of $\boldsymbol{\Phi}$ respectively. The 97 matrix $\Phi$ reads: 


$$
\boldsymbol{\Phi}=\left[\begin{array}{cccc}
4.315050777 & -0.1833177904 & 0.01642021976 & -4.829962430 \mathrm{E}-4 \\
-5.148136502 & -0.3554678337 & -9.974634025 \mathrm{E}-4 & 4.975387379 \mathrm{E}-4 \\
2.385888075 & 1.339974300 & -0.05966399650 & 7.544565390 \mathrm{E}-4 \\
-0.2810124370 & -0.8040552990 & 0.04491874691 & -7.869467548 \mathrm{E}-4
\end{array}\right]
$$

98

Figure 3 shows the numerical points obtained in the FE simulations (each point corresponds to one simulation) and the surface fitting function of equation (6).

[Fig. 3 about here.]

Figure 4 shows the relation between $\phi$ and $\alpha$ for different values of the dimensionless elastic parameter $\rho$ obtained by the polynomial approximation and by the FE model. It can be noticed that the fitting obtained is excellent. The curve with $\rho=1$ corresponds to the isotropic case. The close range $\rho \in[0,20]$ should cover all the practical applications. For example for a IM7$8552[0 / 90]_{n \mathrm{~s}}$ laminate $\left(E_{1}=171420 \mathrm{MPa}, E_{2}=9080 \mathrm{MPa}, G_{12}=5290 \mathrm{MPa}\right.$, $\left.\nu_{12}=0.32\right)$ the elastic parameters calculated using the classical lamination theory are $E_{x}=E_{y}=90648 \mathrm{MPa}, G_{x y}=5290 \mathrm{MPa}, \nu_{x y}=\nu_{x y}=0.032$ and, from $(2), \rho=8.54$.

[Fig. 4 about here.]

After defining $\phi$, it is observed that the energy release rate $\mathcal{G}(a)$ is an increasing function of the crack length, or, in other words, the proposed specimen has a positive geometry [17]. Equation (5) can be re-written as: 


$$
\mathcal{G}_{I}(a+\Delta a)=\frac{1}{4 w E} \sqrt{\frac{1+\rho}{2}}\left(\frac{P}{t}\right)^{2} \phi\left(\alpha_{0}+\frac{\Delta a}{w}, \rho\right)
$$

115

where $\alpha_{0}=a_{0} / w$ (see Fig. 1$)$. The energy release rate $\mathcal{G}_{I}(a+\Delta a)$ and the schematic representation of the R-curve of the material $\mathcal{R}_{I}(\Delta a)$ are shown in Fig. 5. The dotted line represents the $\mathcal{G}_{I}(a+\Delta a)$ at a constant load $P$. The crack cannot propagate at a constant load if $\mathcal{G}_{I}<\mathcal{R}$ while it will propagate dynamically if $\mathcal{G}_{I}>\mathcal{R}$. The dashed line in Fig. 1, tangent at the R-curve, represents the crack-driving force at the peak load, $P_{u}$ (or at the maximum remote stress, $\left.\sigma_{u}\right)$.

2

[Fig. 5 about here.]

In summary, for different sizes $w_{k}$ the driving-force curves $\mathcal{G}_{I}$ corresponding at the peak loads $P_{u k}$ are tangent to R-curve, $\mathcal{R}$. This fact will be used to measure the R-curve.

\subsection{Obtaining the $R$-curve from size effect}

$$
\left\{\begin{array}{l}
\mathcal{G}_{I}(a+\Delta a)=\mathcal{R}(\Delta a) \\
\frac{\partial \mathcal{G}_{I}(a+\Delta a)}{\partial \Delta a}=\frac{\partial \mathcal{R}(\Delta a)}{\partial \Delta a}
\end{array}\right.
$$

Assuming that the size effect law, $\sigma_{u}=\sigma_{u}(w)$, is known, substituting (5) in the first of equations (9) yields: 


$$
\frac{1}{E} \sqrt{\frac{1+\rho}{2}} \sigma_{u}^{2} w \phi\left(\alpha_{0}+\frac{\Delta a}{w}\right)=\mathcal{R}(\Delta a)
$$

131 This equation holds for every $w$. Following [17], differentiating (10) with re-

$$
\frac{1}{E} \sqrt{\frac{1+\rho}{2}} \frac{\partial}{\partial w}\left(\sigma_{u}^{2} w \phi\left(\alpha_{0}+\frac{\Delta a}{w}\right)\right)=0
$$

The R-curve, $\mathcal{R}(\Delta a)$, can be obtained solving (11) for $w=w(\Delta a)$, and by replacing this solution in equation (10).

The proposed method provides the R-curve of the laminate. The R-curve of the $0^{\circ}$ plies is obtaining neglecting the fracture toughness of the $90^{\circ}$ plies, as previously proposed by Pinho [6]. The energy balance for self-similar crack propagation da reads:

$$
\mathcal{R} h \mathrm{~d} a=\mathcal{R}_{0} h_{0} \mathrm{~d} a+\mathcal{R}_{90} h_{90} \mathrm{~d} a
$$

where $\mathcal{R}_{0}$ and $\mathcal{R}_{90}$ are the R-curves for the $0^{\circ}$ and $90^{\circ}$ plies respectively while $h, h_{0}$ and $h_{90}$ are respectively the thickness of the laminate, of the $0^{\circ}$ and of the $90^{\circ}$ plies respectively. Taking into account that $\mathcal{R}_{90}<<\mathcal{R}_{0}$, and $h_{0}=$ $h_{90}=h / 2$, equation (12) results in:

$$
\mathcal{R}_{0}=2 \mathcal{R}
$$


Therefore the fracture toughness in longitudinal direction $\mathcal{R}_{0}$ is simply obtained as twice the value of the fracture toughness of the laminate $\mathcal{R}$.

\section{Experiments}

\subsection{Material and specimen configurations}

The material used is the Hexcel IM7-8552 carbon fiber reinforced epoxy. The elastic properties of the material were previously obtained in [18] and are shown in Table 1 , where $E_{1}$ and $E_{2}$ are the longitudinal and the transverse Young's modulus respectively, $G_{12}$ is the shear modulus, and $\nu_{12}$ is the major Poisson's ratio.

[Table 1 about here.]

The $[0 / 90]_{8 \mathrm{~s}}$ layup with a nominal thickness of $4 \mathrm{~mm}$ is used. The laminate was cured in a hot-press according to the manufacturer's specifications. The curing cycle consists of three different stages: i) keeping the laminate at $110^{\circ} \mathrm{C}$ for 1 hour; ii) increasing the temperature up to $180^{\circ} \mathrm{C}$ and keeping this temperature for 2 hours iii) cooling at $3^{\circ} \mathrm{C} / \mathrm{min}$. The pressure of 7 bar was used during all the curing cycle.

After curing, the laminate was cut using a diamond saw disk to the nominal specimens size and the notches were machined using a vertical mill equipped with $1 \mathrm{~mm}$ diameter drill bit.

Six sizes were chosen for the specimens, corresponding to the references A to F. The nominal dimensions of the specimens are shown in Figure 6. Three specimens were tested for each specimen type. It should be noticed that the 
initial crack length $a_{0}$ was chosen to be one-half of the characteristic length for all specimens. Therefore the parameter $\alpha_{0}$ is equal to 0.5 .

[Fig. 6 about here.]

The specimens manufactured are scaled from the specimen shown in Figure 1. It should be noted that in the actual specimen the crack faces are separated by a finite distance of $1 \mathrm{~mm}$. This ensures that there is no contact of the crack faces; such contact would have invalidated the experimental results. It should also be noted that the shape of the crack tip (semicircular, $1 \mathrm{~mm}$ of diameter) does not have an influence on the correct determination of the R-curve of the material because: i) the crack tip shape does not influence the value of the fracture toughness in compression [19], and ii) after the initial propagation the crack tip can be considered sharp and this should not influence the value of the fracture toughness at unstable crack propagation.

After manufacturing, the specimens were painted with a matte white. After drying the specimens, a speckle was made for all the specimens with the help of an airbrush (see Fig. 7).

[Fig. 7 about here.]

\subsection{Photo-mechanical compression tests}

The compression tests were performed with the support of the digital image correlation (DIC) system (Fig. 8). The tests were carried out on a Instron 4208 universal testing machine under displacement control, with a cross-head displacement rate of $0.1 \mathrm{~mm} / \mathrm{min}$ and at room temperature of $22^{\circ} \mathrm{C}$ and relative humidity of $56 \%$. The load was measured using a $100 \mathrm{kN}$ load cell. The 
Spider data acquisition system along with Catman software was used to record the strain gauge signal (in the specimens equipped with a strain gauge). 350 $\Omega$ strain gauges from Vishay Micro-Measurement, C2A-06-062LW-350, were used to verify if buckling occurs in the longest specimens ( $\mathrm{F}$ specimens). To replicate the same frictionless condition imposed numerically for the calculation of the correction factor $\phi$, a thin layer of molybdenum disulfide (MoS2) was used between the specimen and the loading system. The self alignment system shown in Figure 8(b) was also used. The system consists of two parts connected by a spherical joint. The upper part of the self alignment system is in contact with the specimen and it is equipped with a tungsten-carbide insert to prevent indentation; the bottom part is bolted to the frame of the testing machine. By allowing small rotations between the two parts, the self alignment device avoids premature failure of the specimen that may result from possible parallelism errors between the two faces in contact with the loading system.

[Fig. 8 about here.]

At the scale of observation used in this work, the textured pattern required for the digital image correlation was created across the gauge section by means of aerosol and airbrush painting, as shown in Fig. 9. The Aramis DIC-2D v6.0.26 system was used in this work [20,21]. An 8-bit Baumer Optronic FWX20 camera coupled with a Nikon AF Micro-Nikkor 200 mm f/4D IF-ED lens were used for image acquisition. The optical devices and measuring parameters are summarised in Table 2 for each specimen configuration (see also Fig 7).

[Fig. 9 about here.]

A subset size and a subset step of $15 \times 15$ pixel $^{2}$ and $13 \times 13$ pixel $^{2}$ were chosen, respectively (Table 2). In order to guarantee a suitable speckle pattern for this 
virtual gauge an airbrush was used (Iwata Custom 181 Micron CM-B model

with a fluid nozzle of $0.18 \mathrm{~mm}$ in diameter and spray 182 range lower than 60 microns). With this marking technique the accurate uniformity, isotropy and spot size can be achieved. A slightly overlapping of 2 pixels between adjacent subsets was chosen in order to enhance spatial resolution in the strain reconstruction. A strain base length of 5 subsets was selected for strain computation. The displacement and strain resolution of the measured is expected in the range of $2 \times 10^{-2}$ pixel and $0.02-0.04 \%$ respectively (Table 2 ).

\subsection{Experimental results}

[Table 2 about here.]

Representative load vs. displacement curves are shown in Figure 10 for the different specimens.

[Fig. 10 about here.]

The F specimens (the longest specimens) were equipped with a strain gauge on the back side of the specimen (the side without the speckle for the DIC). The strain measured by the strain gauge was compared to the strain measured by the DIC (virtual strain gauge) on the front side in the location corresponding to the physical strain gauge. The strain of the virtual strain gauge was obtained as the average of the longitudinal strain on the rectangular region symmetric to the strain gauge and with the dimension of the electrical grid of the physical strain gauge. Figure 11 shows the comparison between the signal of the physical and of the virtual strain gauge for a representative specimen and the location of the strain gauge in the specimen. As virtually there are no 
differences, it is concluded that no buckling occurred in the test specimens.

[Fig. 11 about here.]

The digital image correlation can be used to further verify the validity of the tests performed. Figure 12 shows the contour plot of the shear strain, $\gamma_{x y}$. The perfect antisymmetry of the strain field with respect to the longitudinal axis of the specimen and the zero value of the shear strain all over the central part of the specimen (and in particular near the crack tip) shows that the loading system used is appropriate. Any misalignment would result in a different field of the shear strain, and mixed mode crack propagation would have occurred.

[Fig. 12 about here.]

The fracture surface for the two types of specimens (A and F) are shown in Figure 13. It is observed in both specimens that the compressive fracture occurred along the direction of the initial notches.

[Fig. 13 about here.]

The summary of the results is shown in Table 3. For each type of specimen the characteristic size $w$, the peak load $P_{u}$, and the standard deviation are reported. The results obtained are used in the following section in the calculation of the R-curve.

[Table 3 about here.] 


\section{Obtaining the R-curve from size effect}

As previously explained, the use of the size effect method to obtain the Rcurve of the material requires the knowledge of the size-effect law $\sigma_{u}=\sigma_{u}(w)$ that relates the nominal remote stress to the characteristic size of the body. According to Bažant and Planas [17] different kind of regression plots can be used to find the size-effect laws: i) bilogarithmic plot (ln $\sigma_{u}$ vs. $\left.\ln w\right)$; ii) linear regression I ( $\sigma^{-2}$ vs. $\left.w\right)$; iii) linear regression II $\left((\sigma w)^{-2}\right.$ vs. $\left.1 / w\right)$; iv) inverse bilogaritmic plot ( $\ln w$ vs. $\ln \sigma_{u}$ ). Those methods yield approximatively the same results.

After the inspection of the data obtained experimentally and reported in Table 3, the linear regression I was selected. Figure 14 shows $\sigma^{-2}$ as a function of the characteristic size $w$. The experimental points and the linear fitting are also reported.

[Fig. 14 about here.]

The size effect law of the material can be expressed as:

$$
\sigma_{u}=(m w+q)^{-\frac{1}{2}}
$$

where $m$ and $q$ are the slope and the intercept of the linear fit respectively. It should be noted that the linear fit was obtained with a coefficient of determination of $R^{2}=0.92$.

Knowing the size effect law, equation (11) can be solved for $w=w(\Delta a)$. All the other parameters are known: $\alpha_{0}=0.5, E=90648 \mathrm{MPa}$, and $\rho=8.54$. Substituting $w=w(\Delta a)$ in equation (10) enables the calculation of the R- 
curve of the laminate, $\mathcal{R}$. Finally $\mathcal{R}_{0}$ is obtained by multiplying by two the value of $\mathcal{R}$ for every $(\Delta a)$

Figure 15 shows the $\mathcal{R}_{0}$ obtained using this methodology as the envelope of the crack driving force curves. The value of the steady-state value of the fracture toughness can be obtained as:

$$
\mathcal{R}_{s s}=\lim _{w \rightarrow \infty} \mathcal{R}_{0}=\frac{\sqrt{2(1+\rho)}}{E} \frac{\phi_{0}}{m}=61 \mathrm{~kJ} / \mathrm{m}^{2}
$$

where $\phi_{0}=\left.\phi\right|_{\alpha=\alpha_{0}}$. It is interesting to note that the value of the fracture toughness previously measured using the compact compression test specimens [7], $47.5 \mathrm{~kJ} / \mathrm{m}^{2}$, corresponds to just one point in the rising R-curve.

The length of fracture process zone reads [17]:

$$
l_{f p z}=\frac{f_{0}}{2 f_{0}^{\prime}} w_{0}
$$

where $f_{0}=\left.\sqrt{\phi}\right|_{\alpha=\alpha_{0}}, f_{0}^{\prime}=\partial \sqrt{\phi} /\left.\partial \alpha\right|_{\alpha=\alpha_{0}}$ and $w_{0}$ is the constant of Bažant sizeeffect law with the dimension of a length. For the linear regression used [17] $w_{0}=q / m$; therefore equation (16) reads:

$$
l_{f p z}=\frac{f_{0}}{2 f_{0}^{\prime}} \frac{q}{m}=1.43 \mathrm{~mm}
$$

[Fig. 15 about here.]

To simplify the use of the R-curve it is necessary to express it in an analytical form that fits the points obtained by solving equations (10) and (11). The following expression can be used [17]: 


$$
\begin{cases}\mathcal{R}_{0}=\mathcal{R}_{s s}\left[1-(1-\kappa \Delta a)^{n}\right] & \text { if } \Delta a<l_{F P Z} \\ \mathcal{R}_{0}=\mathcal{R}_{s s} & \text { if } \Delta a \geq l_{F P Z}\end{cases}
$$

By optimal fitting the following values are obtained: $\kappa=0.5126$ and $n=4.289$.

Figure 16 shows the analytical fitting of the R-curve.

[Fig. 16 about here.]

\section{Conclusion}

This paper demonstrates that it is possible to obtain the compressive R-curve of the longitudinal plies of carbon-epoxy laminates by quantifying the size effect law observed in compressive tests of scaled specimens with two edge cracks. The limiting factors of the previously proposed compact compression test method, such as the difficulty in predicting the exact location of the extremity of the kink band, do not play any role in the model developed in this paper.

Using both electrical strain gauges and the digital image correlation system it is demonstrated that the test method and specimens' geometry proposed do not result in premature buckling failure. In addition, the strain field measured by digital image correlation system indicates that the specimens are properly aligned. Therefore, the peak loads measured in the tests can be confidently used for the definition of the size effect law.

While the previous tests methods are only able to provide one single value for the compressive fracture toughness, the proposed method enables the identification of the full R-curve. The steady-state value of the fracture toughness 
313

314

315

316

of the IM7-8552 carbon-epoxy composite material is $61 \mathrm{~kJ} / \mathrm{m}^{2}$, corresponding to a length of the fracture process zone of $1.43 \mathrm{~mm}$.

The work presented in this paper can be used as the basis for material screening and selection, to identify cohesive laws used in the recent analysis models, and to estimate the fracture toughness of multidirectional laminates using the fracture toughness of the $0^{\circ}$ plies.

\section{Acknowledgements}

This work was funded by AIRBUS under the project 2genComp - Second generation composite structural mechanics. The authors gratefully acknowledge the support provided by AIRBUS.

The first and second authors would like to acknowledge the support of the Portuguese Foundation for Science and Technology under the grant FCTDFRH-SFRH-BPD-78104-2011 and Ciência 2008 program, respectively.

\section{References}

[1] Vogler M, Rolfes R, Camanho PP. Modeling the inelastic deformation and fracture of polymer composites part I: Plasticity model. Mechanics of Materials, $59(0): 50-64,2013$.

[2] Camanho PP, Bessa MA, Catalanotti G, Vogler G, Rolfes R. Modeling the inelastic deformation and fracture of polymer composites part II: Smeared crack model. Mechanics of Materials, 59(0):36 - 49, 2013.

[3] Lapczyk I, Hurtado JA. Progressive damage modeling in fiber-reinforced 
materials. Composites Part A: Applied Science and Manufacturing, 38(11):2333 - 2341, 2007.

[4] Donadon MV, Iannucci L, Falzon BG, Hodgkinson JM, de Almeida SFM. A progressive failure model for composite laminates subjected to low velocity impact damage. Computers \& Structures, 86(11-12):1232 - 1252, 2008.

[5] Raimondo L, Iannucci L, Robinson P, Curtis PT. A progressive failure model for mesh-size-independent FE analysis of composite laminates subject to lowvelocity impact damage. Composites Science and Technology, 72(5):624 - 632, 2012.

[6] Pinho ST, Robinson P, Iannucci L. Fracture toughness of the tensile and compressive fibre failure modes in laminated composites. Composites Science and Technology, 66:2069-2079, 2006.

[7] Catalanotti G, Camanho PP, Xavier J, Dávila CG, Marques AT. Measurement of resistance curves in the longitudinal failure of composites using digital image correlation. Composites Science and Technology, 70(13):1986 - 1993, 2010.

[8] Laffan MJ, Pinho ST, Robinson P, McMillan AJ. Translaminar fracture toughness testing of composites: A review. Polymer Testing, 31(3):481 - 489, 2012.

[9] Blanco N, Pinho ST, Robinson P. Design and analysis of a compact tension (CT) specimen for intralaminar fracture toughness characterisation of woven composite laminates. In ECCM 13, 13th European Conference on Composite Materials, Stockholm, June 2 - 5, 2008.

[10] Bažant ZP, Kim J-JH, Daniel IM, Becq-Giraudon E, ZI G. Size effect on compression strength of fiber composites failing by kink band propagation. Int. J. Fracture, 95:103-141, 1999.

[11] Moran PM, Liu XH, Shih CF. Kink band formation and band broadening in 
fiber composites under compressive loading. Acta Metallurgica et Materialia, 43(8):2943 - 2958, 1995.

[12] Fleck NA, Sutcliffe MPF, Sivanshanker S, Xin XJ. Compressive failure of composites due to microbuckle growth. European Journal of Mechanics A/Solids, 16:65-82, 1997.

[13] Suo Z, Bao G, Fan B, Wang TC. Orthotropy rescaling and implications for fracture in composites. Int. J. Solids and Structures, 28:235-248, 1990.

[14] Lutz M. Learning Python. O’Reilly Media, Inc., 3rd edition, 2008.

[15] Dassault Systèmes. Abaqus Version 6.8-3 Documentation, 2008.

[16] Krueger R. The virtual crack closure technique: History, approach and applications. Technical Report NASA/CR-2002-211628 ICASE Report No. 2002-10, ICASE, Hampton, Virginia, April 2002.

[17] Bažant ZP, Planas J. Fracture and Size Effect in Concrete and Other Quasibrittle Materials. CRC Press LLC, 1997.

[18] Camanho PP, Maimí P, Dávila CG. Prediction of size effects in notched laminates using continuum damage mechanics. Composites Science and Technology, 67(13):2715-2727, 2007.

[19] Jackson WC, Ratcliffe JG. Measurement of fracture energy for kink-band growth in sandwich specimens. In Proceedings of the 2nd international conference on composites testing and model identification, Comptest 2004, University of Bristol, Bristol, U.K., 2004.

[20] Xavier J, de Jesus A, Morais J, Pinto J. Stereovision measurements on evaluating the modulus of elasticity of wood by compression tests parallel to the grain. Construction and Building Materials, 26:207-215, 2012.

[21] GOM (www.gom.com). ARAMIS, User Manual - Software - v6.0.2-6, 2009. 
386 1 Double edge notched compression specimen.

${ }_{387} 2$ Finite element model of the specimen.

388

389

390

391

392

393

394

395

396

\section{List of Figures} measurements (region of interest of $1543 \times 1025$ pixel $^{2}$ $\left.\left(22.0 \times 14.6 \mathrm{~mm}^{2}\right)\right)$. $\mathrm{D}$ and $\mathrm{F}$. virtual (DIC) strain gauge.

3 Relation between $\phi$ and $\alpha$ for different values of $\rho$. 24

$4 \quad$ Numerical points and $\phi$ for different values of $\rho$. 25

$\begin{array}{lll}5 & \text { Crack driving force and resistance curves. } & 26\end{array}$

$6 \quad$ Specimens' geometry (dimensions in $\mathrm{mm}$ ). 27

7 Specimens' configuration. 28

$8 \quad$ Photomechanical set-up. 29

$9 \quad$ Speckle pattern typically used in the digital image correlation

10 Typical load displacement curves for the specimens A, B, C,

11 Comparison between the signal of the physical (SG) and

12 Typical contour plot of the shear strain, $\gamma_{x y}$. 33

13 Tested specimens (not at scale). 34

$14 \sigma_{u}^{-2}$ vs. $w$ and linear fitting. 35

15 Envelope of driving force curves and R-curve. 36

16 Analytical fitting of the R-curve. 37 


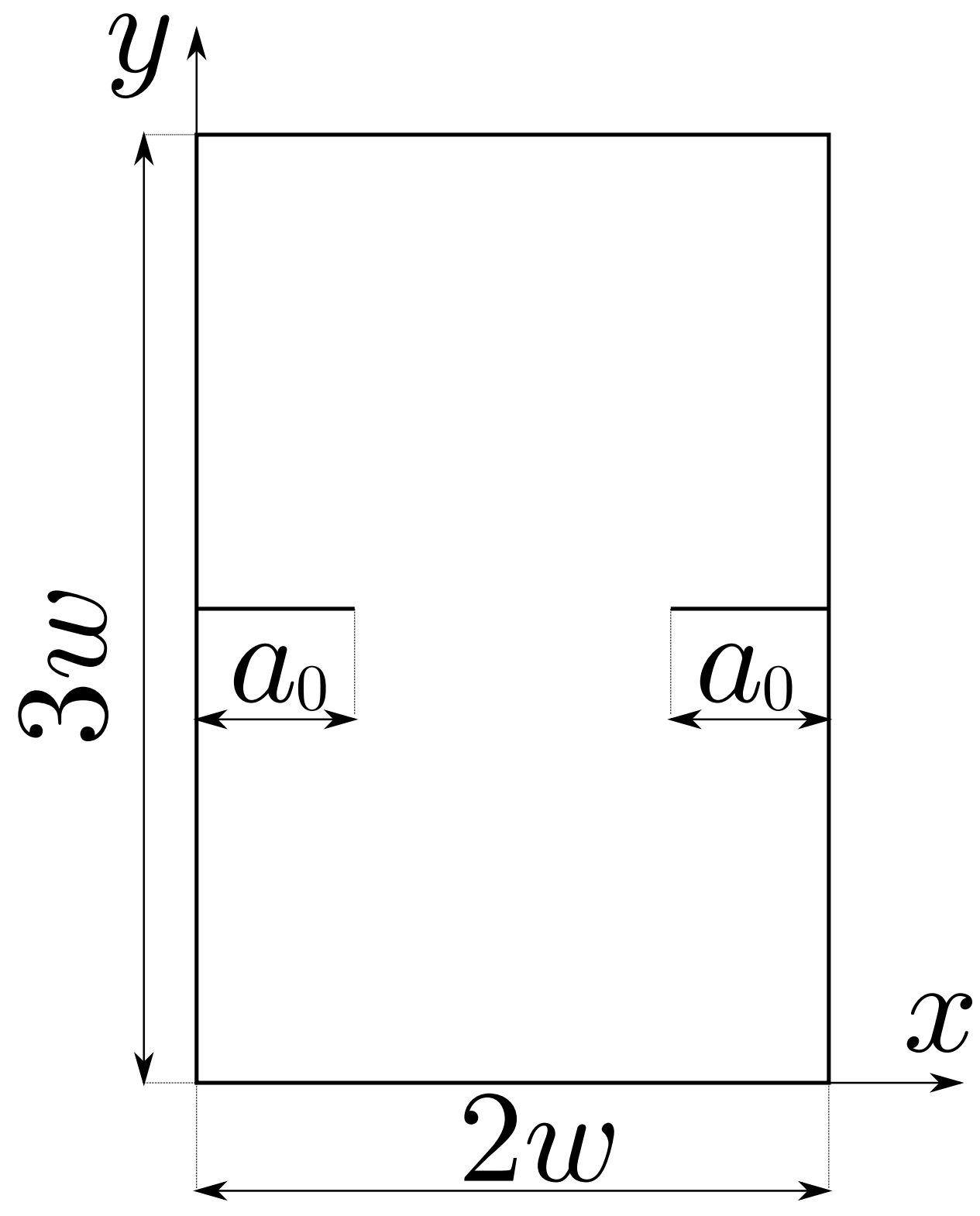

Fig. 1. Double edge notched compression specimen. 
Fig. 2. Finite element model of the specimen.

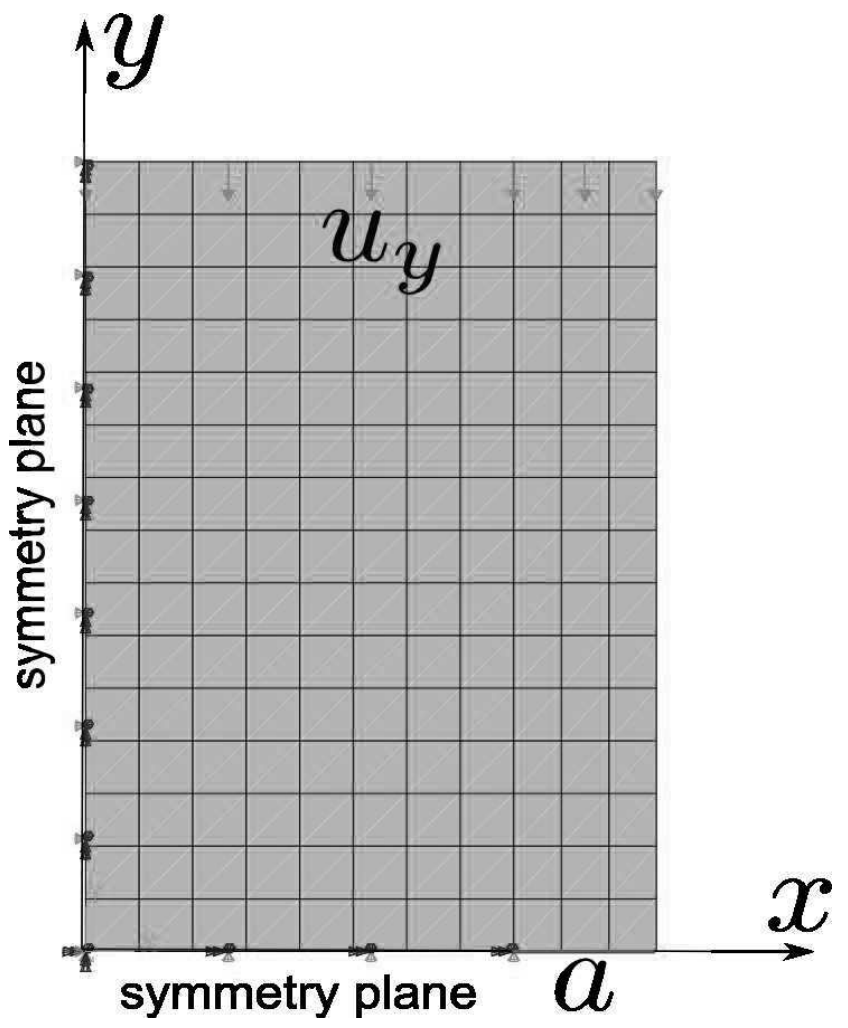




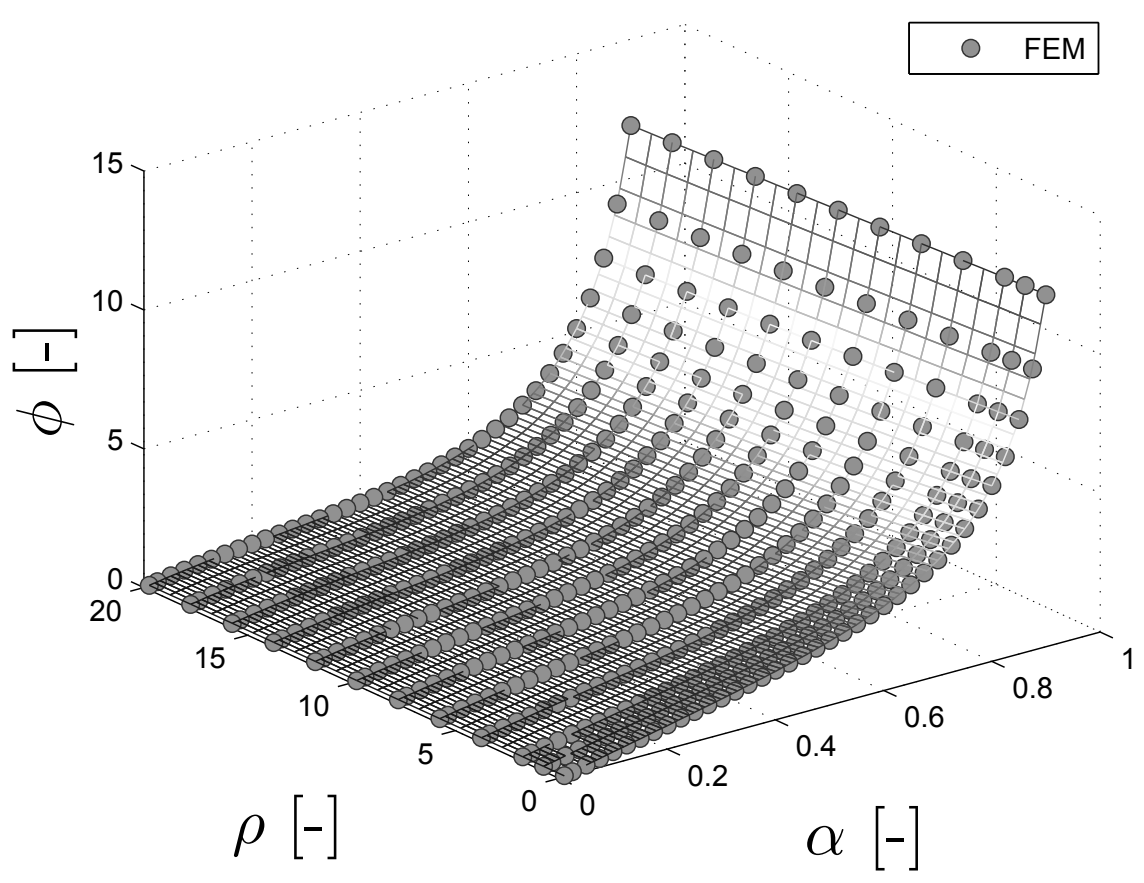

Fig. 3. Relation between $\phi$ and $\alpha$ for different values of $\rho$. 


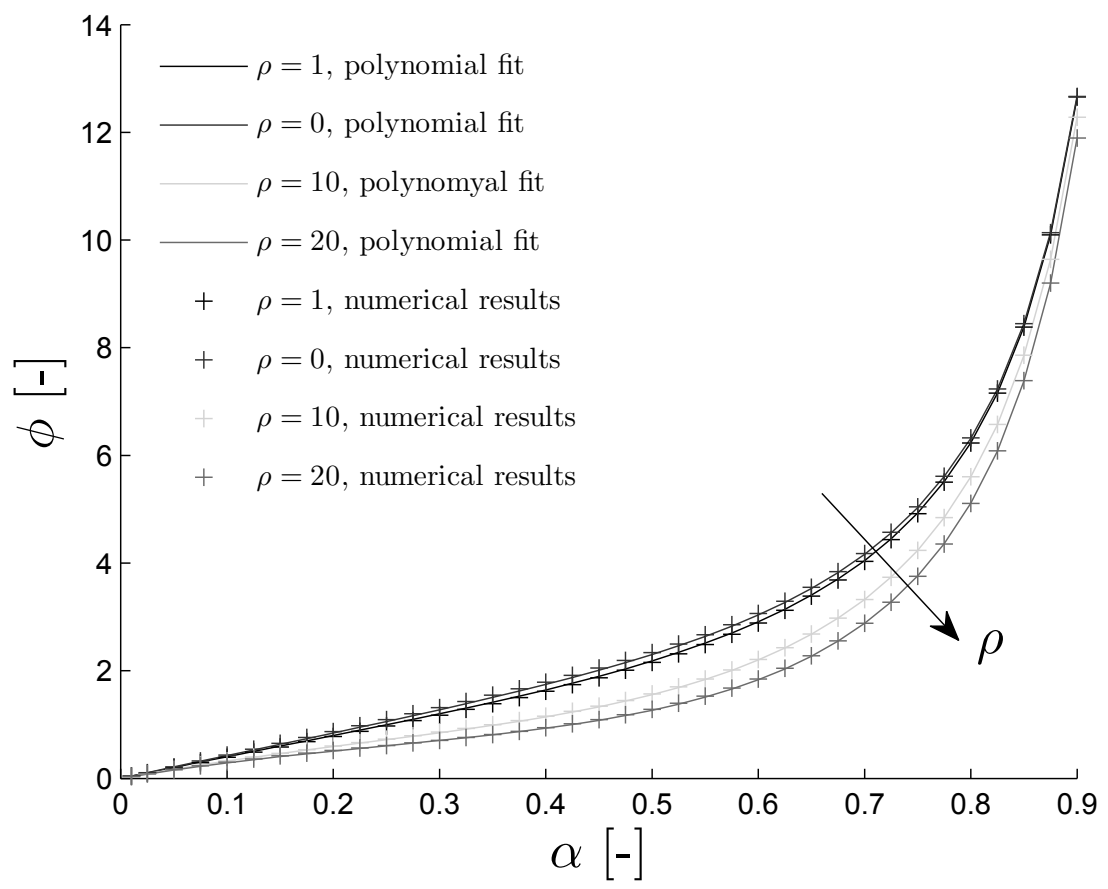

Fig. 4. Numerical points and $\phi$ for different values of $\rho$. 


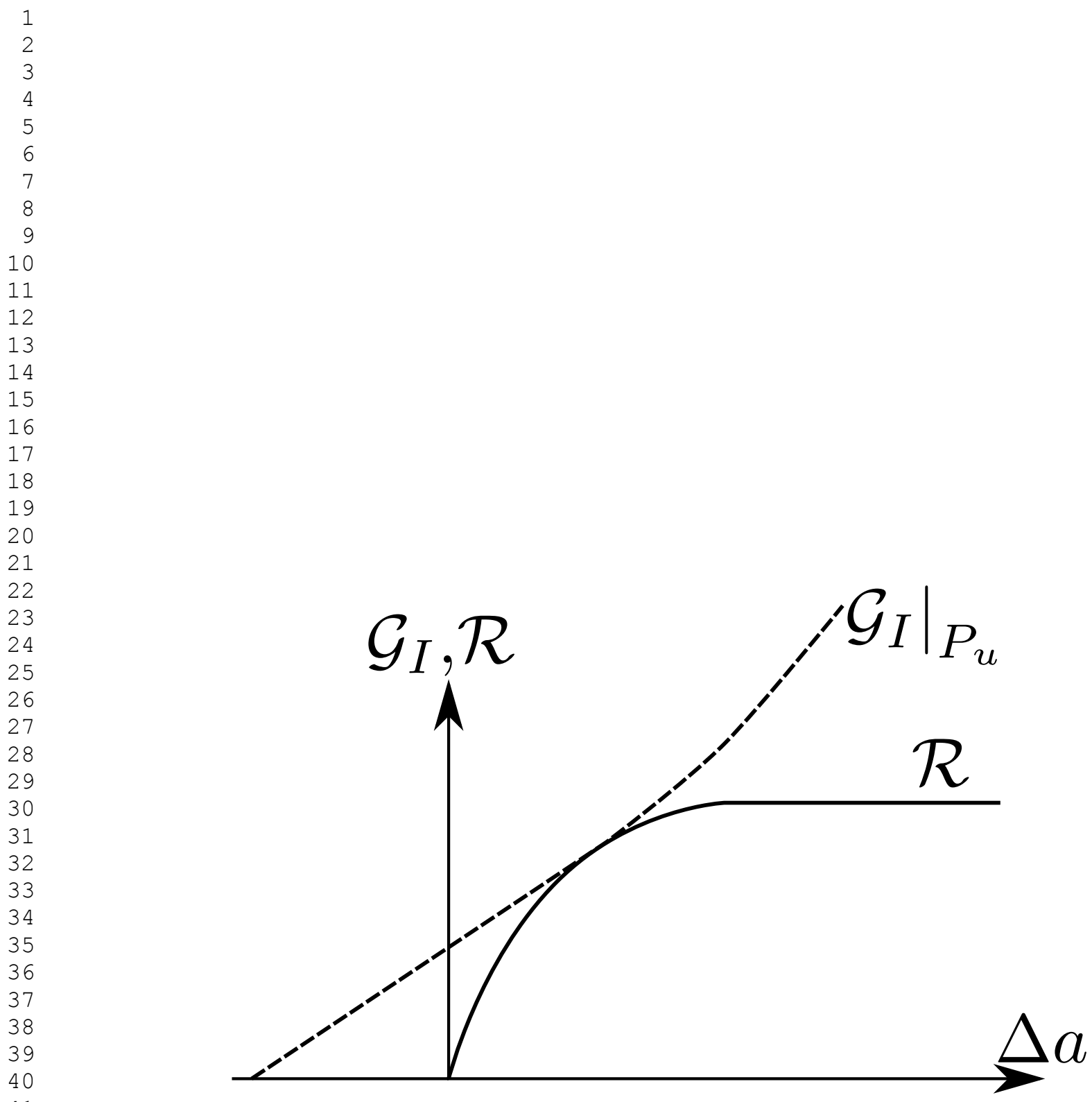

Fig. 5. Crack driving force and resistance curves. 

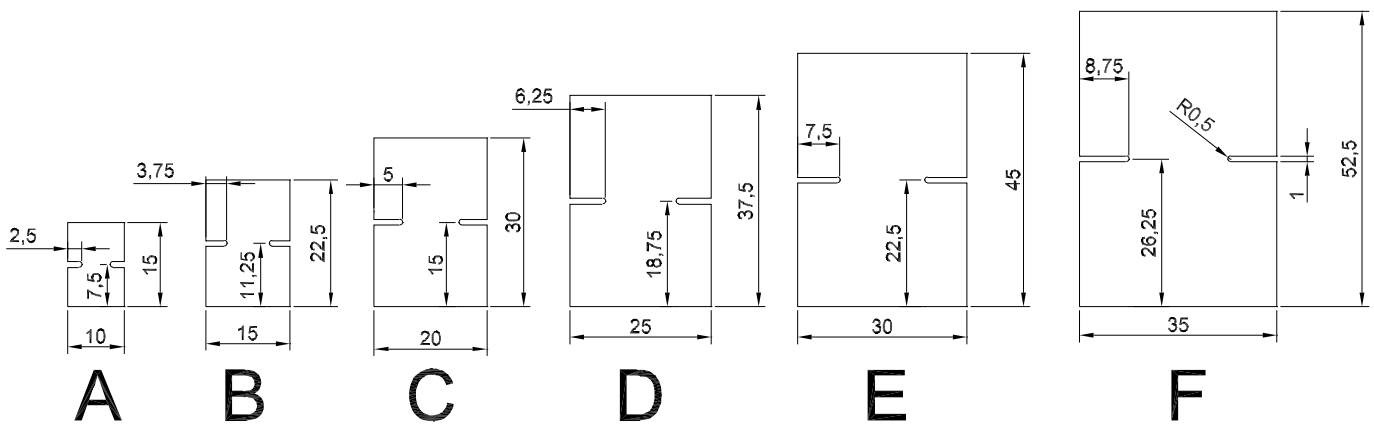

Fig. 6. Specimens' geometry (dimensions in $\mathrm{mm}$ ). 


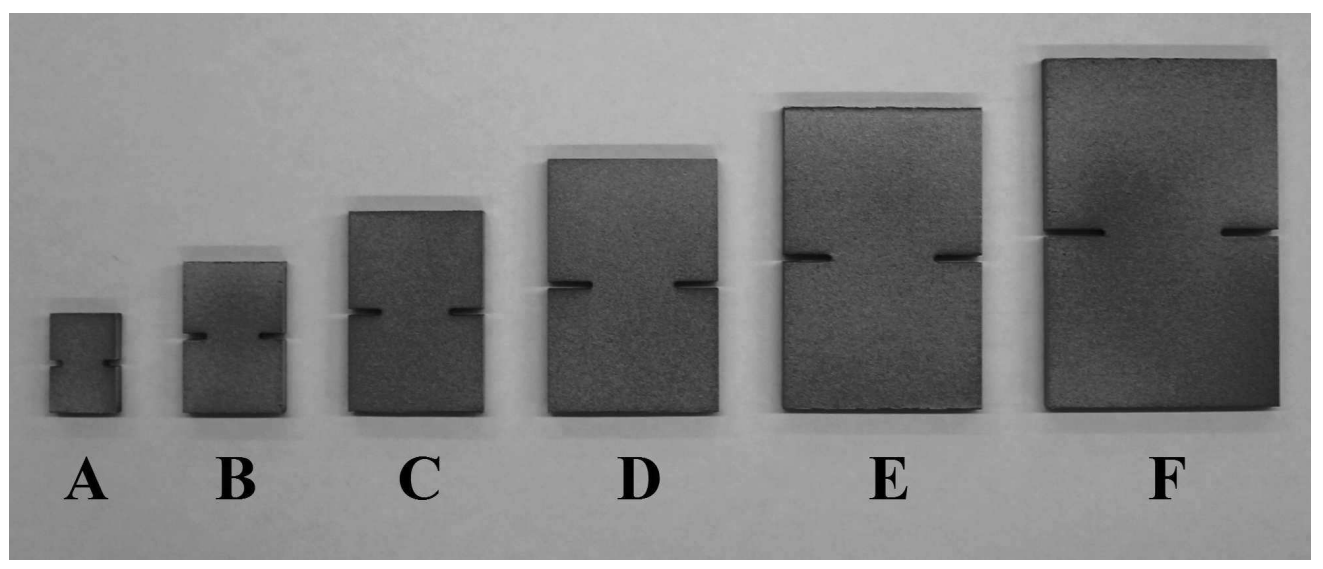

Fig. 7. Specimens' configuration. 


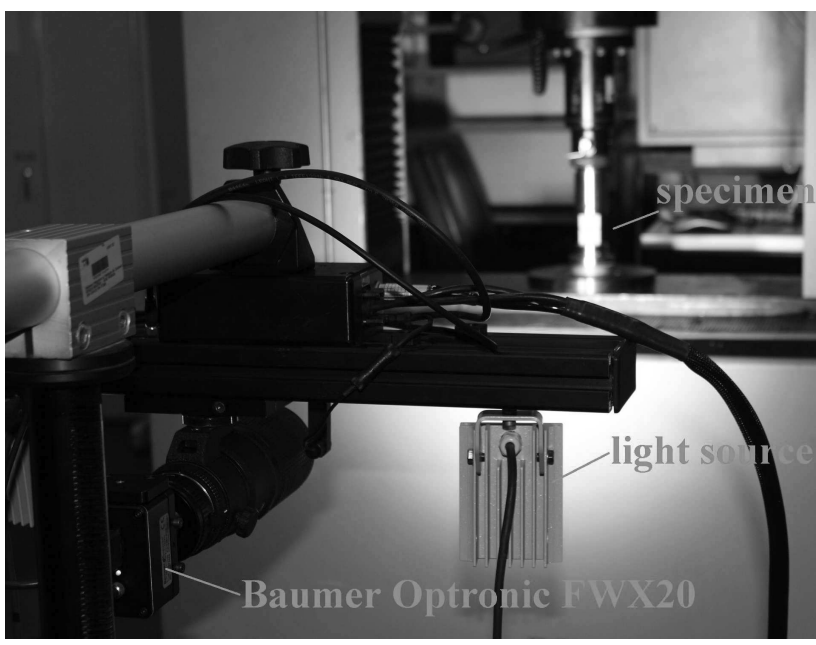

(a) Optical set-up

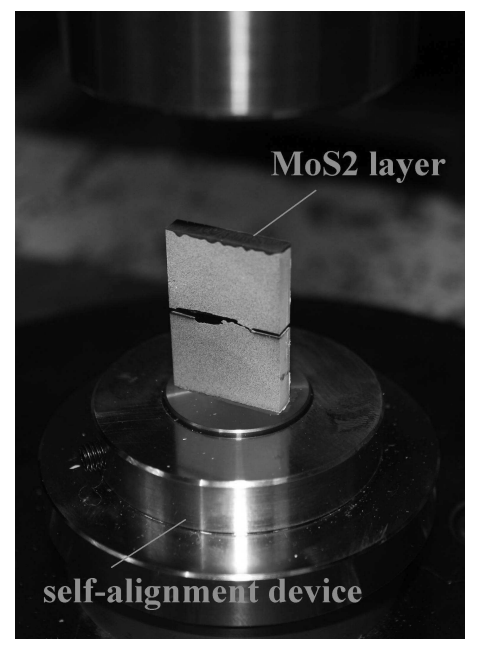

(b) Loading system

Fig. 8. Photomechanical set-up. 

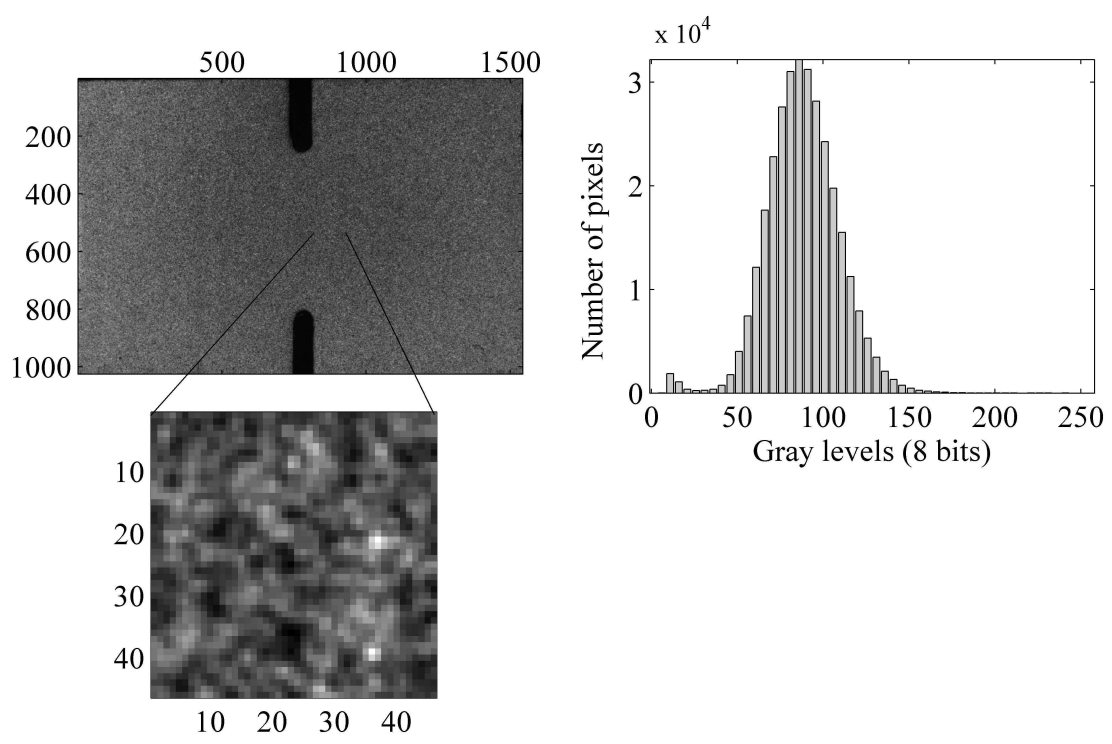

Fig. 9. Speckle pattern typically used in the digital image correlation measurements (region of interest of $1543 \times 1025 \mathrm{pixel}^{2}\left(22.0 \times 14.6 \mathrm{~mm}^{2}\right)$ ). 


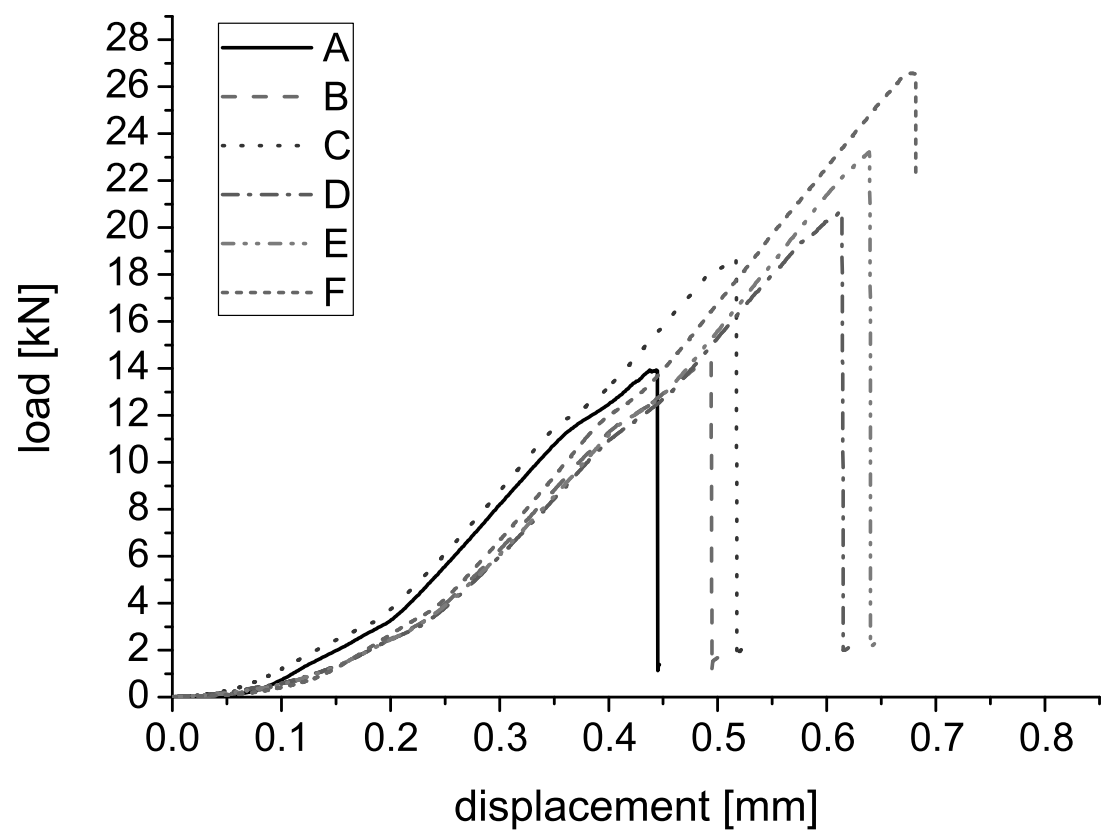

Fig. 10. Typical load displacement curves for the specimens A, B, C, D and F. 
Fig. 11. Comparison between the signal of the physical (SG) and virtual (DIC) strain gauge. 


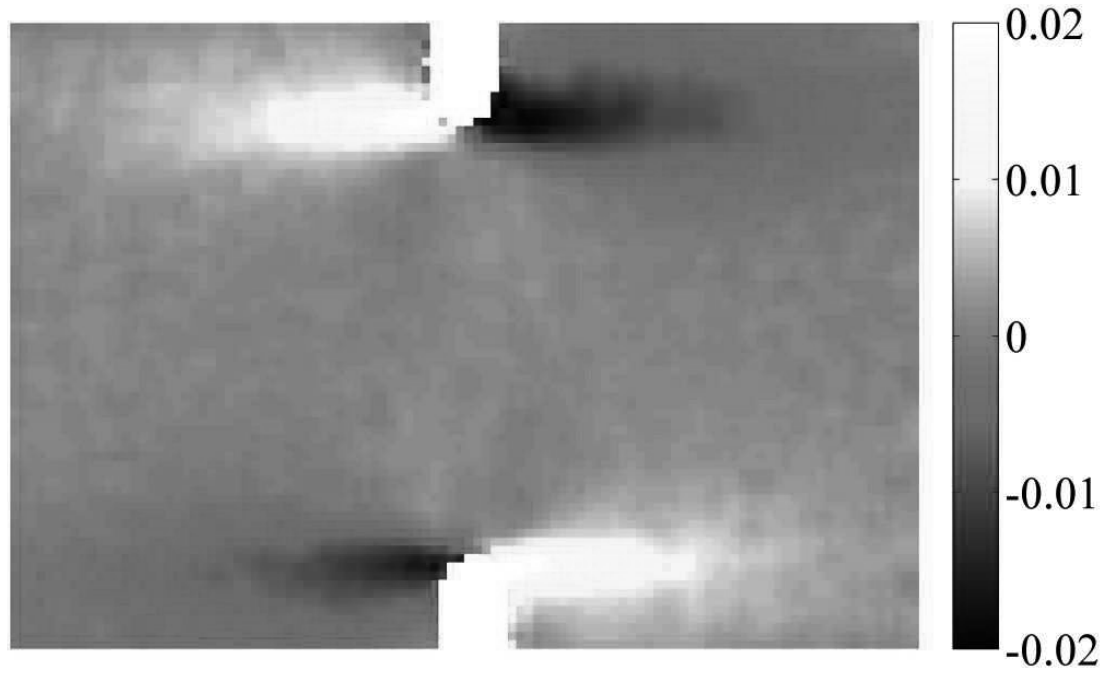

Fig. 12. Typical contour plot of the shear strain, $\gamma_{x y}$. 


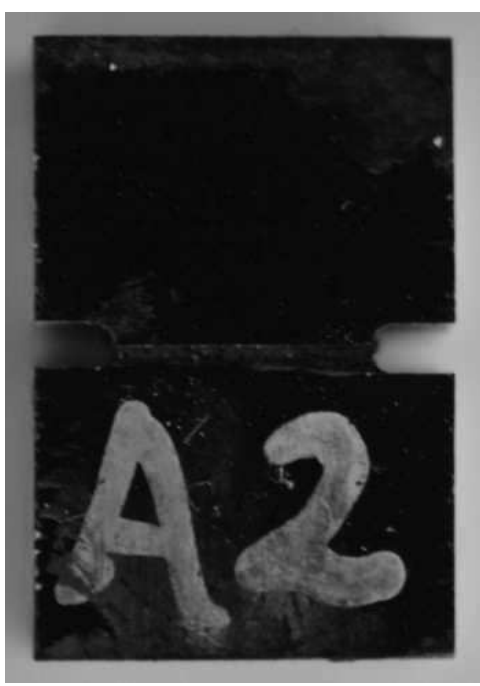

(a) type $\mathrm{A}$

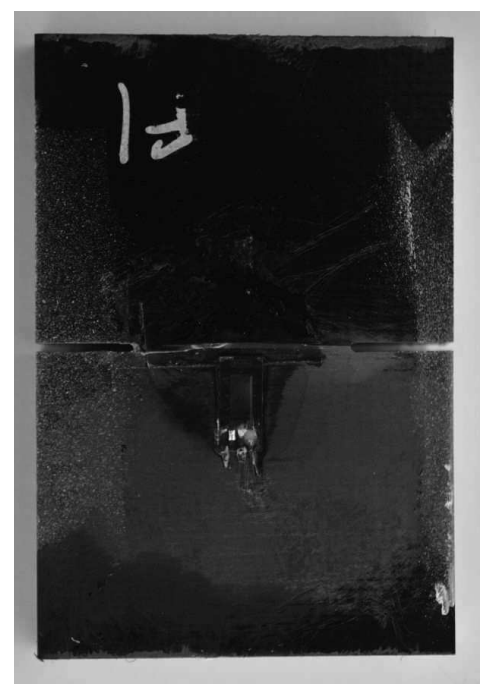

(b) type $\mathrm{F}$

Fig. 13. Tested specimens (not at scale). 


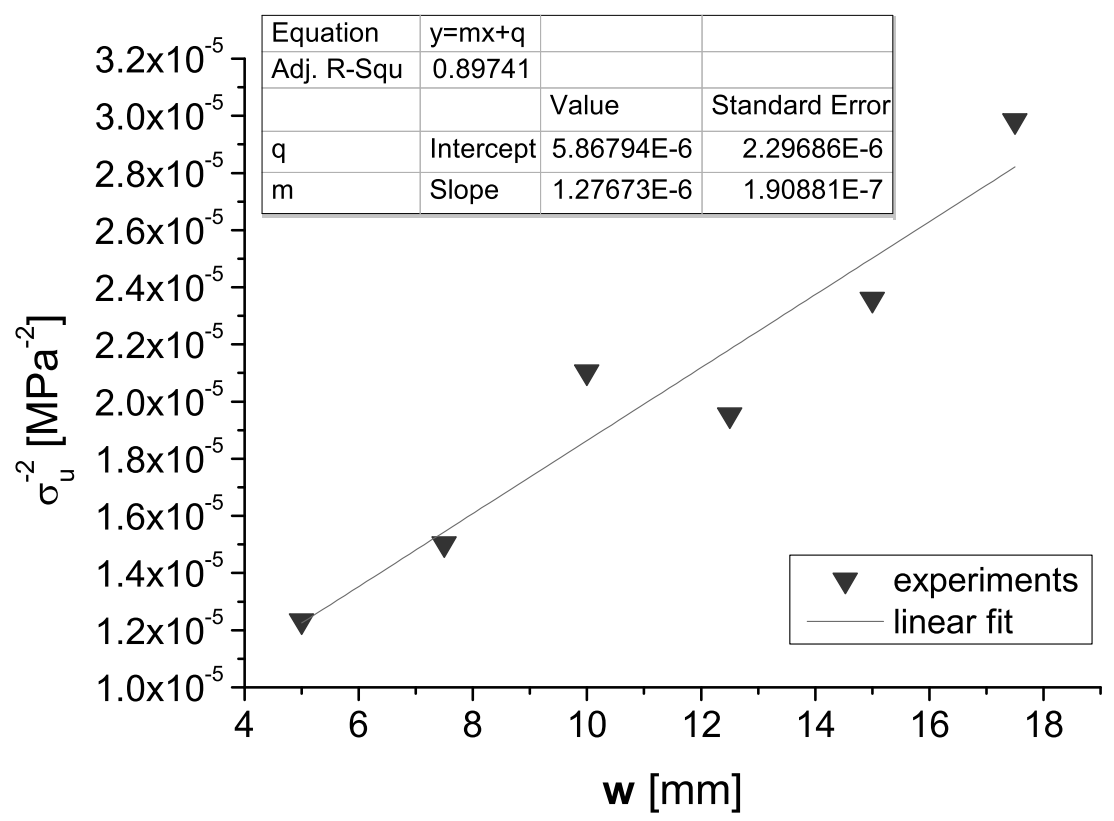

Fig. 14. $\sigma_{u}^{-2}$ vs. $w$ and linear fitting. 


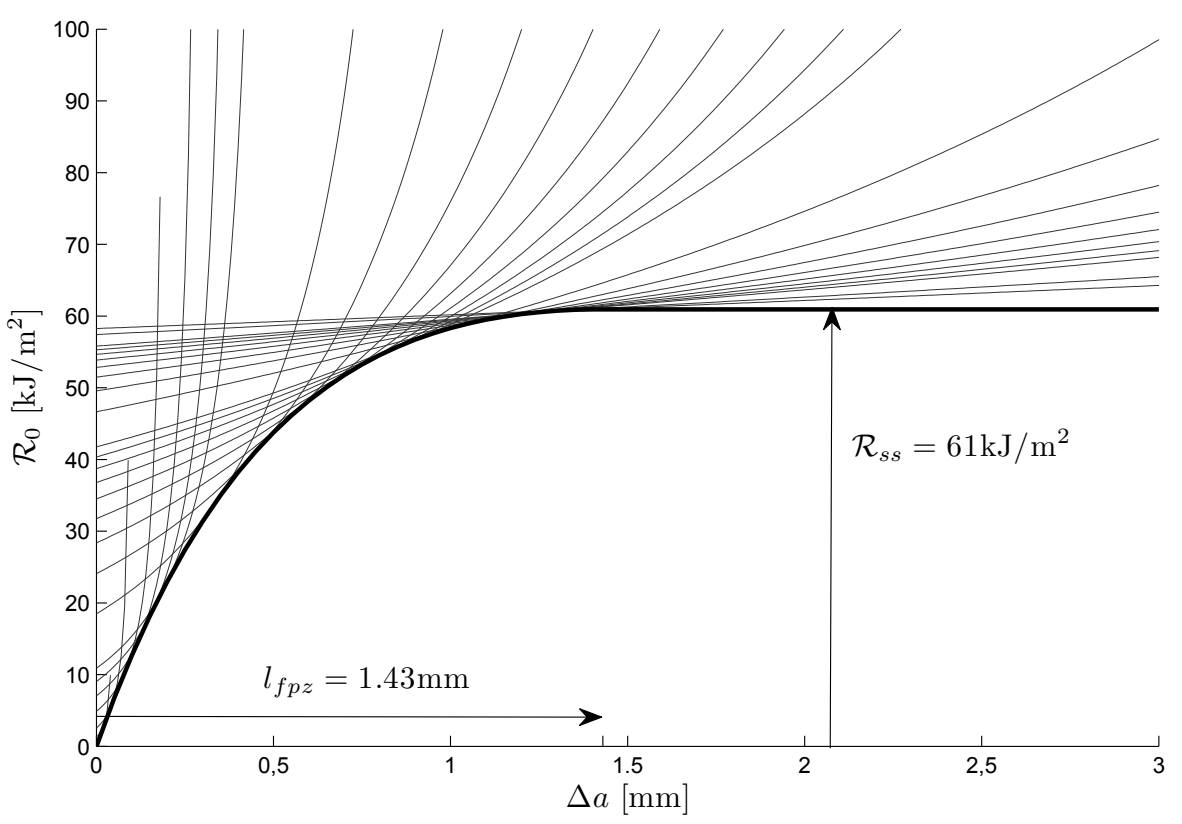

Fig. 15. Envelope of driving force curves and R-curve. 


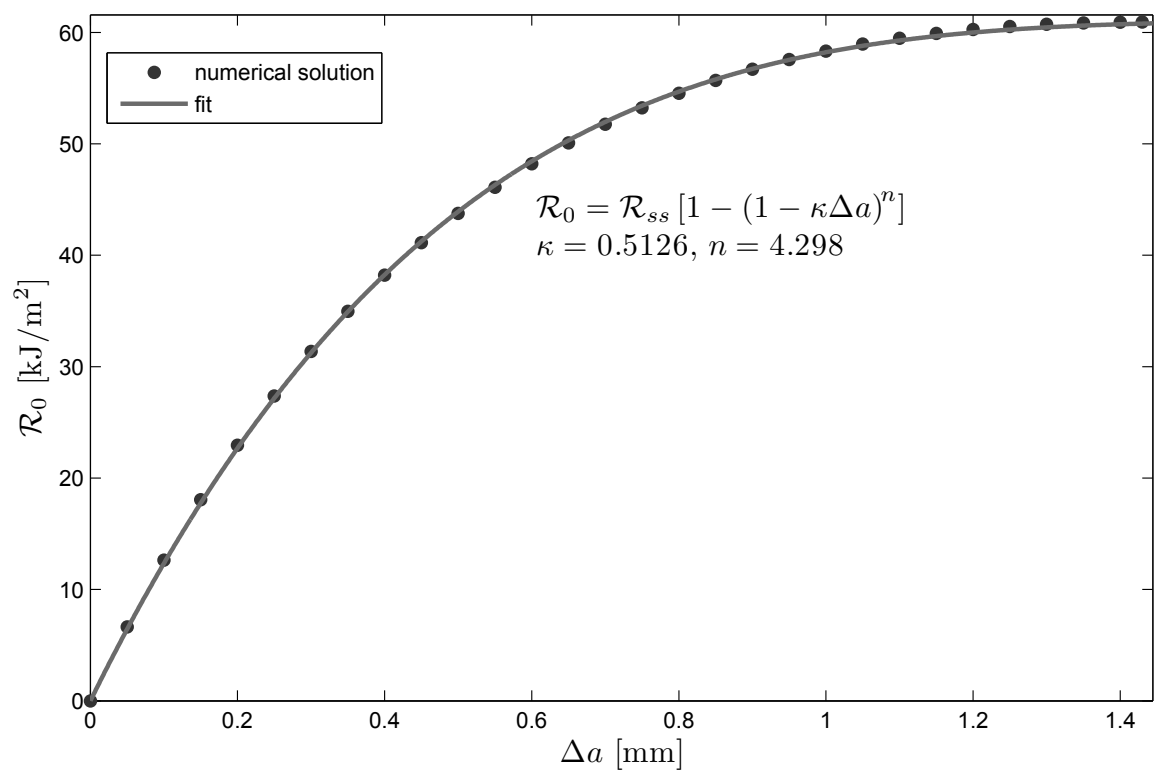

Fig. 16. Analytical fitting of the R-curve. 
406

${ }_{407} 1$ Elastic properties of IM7-8552.

4082 Optical system components and measurement parameters (see

409

410

\section{List of Tables}

Fig. 7 for A, B, C, D, E and F specimen configuration).

3 Summary of the experimental results.
39

41 


\section{Table 1}

\begin{tabular}{cccc}
\hline \hline$E_{1}[\mathrm{MPa}]$ & $E_{2}[\mathrm{MPa}]$ & $G_{12}[\mathrm{MPa}]$ & $\nu_{12}$ \\
\hline 171420 & 9080 & 5290 & 0.32 \\
\hline \hline
\end{tabular}

Elastic properties of IM7-8552. 
Table 2

Optical system components and measurement parameters (see Fig. 7 for A, B, C, D, E and F specimen configuration).

\begin{tabular}{|c|c|c|c|c|c|c|}
\hline \multirow[t]{2}{*}{ CCD camera } & \multicolumn{6}{|c|}{ Baumer Optronic FWX20 } \\
\hline & (8 bit, 1624 & 1236 pixels) & & & & \\
\hline \multirow[t]{2}{*}{ Lens } & \multicolumn{6}{|c|}{ Nikon AF Micro-Nikkor 200 mm f/4D IF-ED } \\
\hline & \multicolumn{6}{|c|}{ (Working F-number: 11) } \\
\hline Lighting system & \multicolumn{6}{|c|}{ LED RAYLUX 25} \\
\hline Image recording & $\mathrm{A}$ & $\mathrm{B}$ & $\mathrm{C}$ & $\mathrm{D}$ & $\mathrm{E}$ & $\mathrm{F}$ \\
\hline \multicolumn{7}{|l|}{ Field Of View } \\
\hline$\left(\mathrm{mm}^{2}\right)$ & $15.2 \times 11.5$ & $23.2 \times 17.7$ & $31.2 \times 23.7$ & $38.8 \times 29.5$ & $46.2 \times 35.1$ & $55.3 \times 42.1$ \\
\hline \multicolumn{7}{|l|}{ Working Distance } \\
\hline$(\mathrm{mm})$ & 560 & 750 & 1000 & 1250 & 1420 & 1690 \\
\hline \multicolumn{7}{|l|}{ Conversion factor } \\
\hline$(\mathrm{mm} / \mathrm{pixel})$ & 0.0093 & 0.0143 & 0.0192 & 0.0239 & 0.0284 & 0.034 \\
\hline \multicolumn{7}{|l|}{ Acquisition frequency } \\
\hline$(\mathrm{Hz})$ & 1 & 1 & 1 & 0.5 & 0.5 & 0.5 \\
\hline Exposure time (ms) & 4 & 4 & 7 & 7 & 12 & 20 \\
\hline \multicolumn{7}{|c|}{ DIC (Aramis) parameters } \\
\hline Subset size & \multicolumn{6}{|c|}{$15 \times 15$ pixels $^{2}$} \\
\hline Subset step & \multicolumn{6}{|c|}{$13 \times 13$ pixels $^{2}$} \\
\hline Strain base length & \multicolumn{6}{|c|}{$5 \times 5$ subsets } \\
\hline \multicolumn{7}{|l|}{ DIC resolution } \\
\hline Displacement & \multicolumn{6}{|c|}{$2 \times 10^{-2}$ pixel } \\
\hline Strain & \multicolumn{6}{|l|}{$0.02-0.04 \%$} \\
\hline
\end{tabular}




\begin{tabular}{lcccccc}
\hline \hline specimen label & $\mathrm{A}$ & $\mathrm{B}$ & $\mathrm{C}$ & $\mathrm{D}$ & $\mathrm{E}$ & $\mathrm{F}$ \\
\hline$w[\mathrm{~mm}]$ & 5 & 7.5 & 10 & 12.5 & 15 & 17.5 \\
$P_{u}[\mathrm{~N}]$ & 11390 & 15477 & 17436 & 22622 & 24706 & 25628 \\
$\operatorname{STDV}\left(P_{u}\right)[\mathrm{N}]$ & 2262 & 1421 & 3268 & 1793 & 1827 & 1028 \\
$\sigma_{u}[\mathrm{MPa}]$ & 285 & 258 & 218 & 226 & 206 & 183 \\
\hline \hline
\end{tabular}

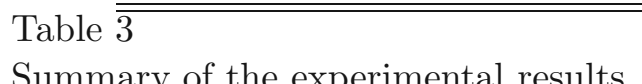

